\title{
CARACTERÍSTICAS E SEGURANÇA DO GLUTAMATO MONOSSÓDICO COMO ADITIVO ALIMENTAR: ARTIGO DE REVISÃO
}

\section{CHARACTERISTICS AND SAFETY OF MONOSODIUM GLUTAMATE AS FOOD ADDITIVE: ARTICLE REVIEW}

Paulo Roberto do Rêgo Monteiro de CARVALHO ${ }^{1,4}$, Vinícius José BOLOGNESI ${ }^{2,4}$, Sandra Mara Woranovicz BARREIRA ${ }^{3,4}$, Carlos Eduardo ROCHA GARCIA ${ }^{3,4}$

'Bolsista de Extensão. Graduando do Curso de Farmácia

${ }^{2}$ Bolsista de Iniciação Científica. Graduando do Curso de Farmácia

${ }^{3}$ Docente do Departamento de Farmácia

${ }^{4}$ Universidade Federal do Paraná. Avenida Pref. Lothário Meissner, 632, CEP 80210170, Curitiba-Pr. Email: carlos.garcia@ufpr.br

\section{RESUMO:}

Este trabalho tem como objetivo revisar as características e segurança no uso do glutamato monossódico (GMS) como aditivo alimentar. Este composto trata-se do sal sódico do ácido glutâmico, um aminoácido não-essencial amplamente encontrado na natureza, utilizado como realçador de sabor capaz de ofertar um gosto diferenciado aos alimentos reconhecido sensorialmente como umami. A produção industrial de GMS, originalmente baseada em seu isolamento a partir do glúten de trigo, foi substituída pela obtenção por meio de processos fermentativos como alternativa para suprir a crescente demanda por este aditivo. $O$ ácido glutâmico é encontrado naturalmente nos alimentos como componente de proteínas e a utilização de seus sais como aditivos é considerada segura pelas principais agências reguladoras, exceto em alimentos destinados a recém-nascidos que ainda requerem maiores estudos para ser considerado inócuo.

Palavras-chave: Ácido glutâmico. Aditivo alimentar. Realçador de sabor. Umami.

\section{ABSTRACT:}

The main purpose of this work was to review the characteristics and safety of monosodium glutamate (MSG) as food additive. This substance is the sodium salt of glutamic acid, a nonessential amino acid widely found in nature. Generally, is used in industry as a flavor enhancer and offers a different taste in food, known as umami._The industrial production of MSG firstly based on its isolation from wheat gluten, was replaced by fermentation processes, a currently alternative applied in industry to supply the growing demand of this additive. MSG is found naturally in foods as a component of proteins and their use as additives. The concentrations usually used in foods are considered safety by leading regulatory agencies, except in foods for infants, in which further studies is required so that their use can be considered harmless.further studies is required so that their use can be considered harmless. 
Key words: Flavour enhancer. Food additive. Glutamic acid. Umami.

\section{INTRODUÇÃO}

O glutamato monossódico (GMS) é o sal sódico do ácido glutâmico (GLU), um aminoácido não essencial amplamente encontrado na natureza, utilizado na indústria com objetivo de melhorar a palatabilidade de diversos produtos alimentícios, de carnes a vegetais industrializados (YAMAGUCHI, 1979; JINAP e HAJEB, 2010) (Figura1).

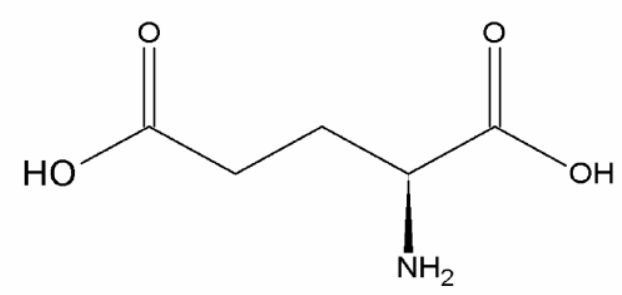

A

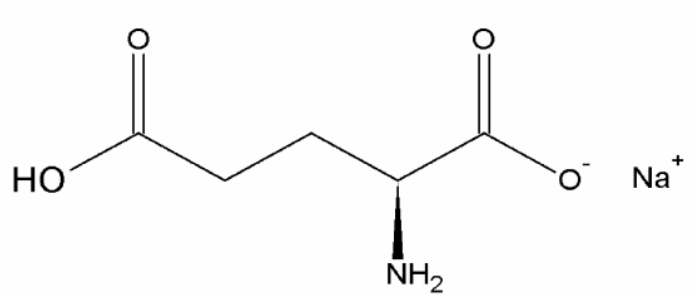

B

Figura 1: Estruturas do ácido glutâmico $(A)$ e glutamato monossódico (B).

O GLU é um importante aminoácido sintetizado em quase todas as células do nosso organismo e precursor do ácido gama-aminobutírico (GABA), ambos atuam como neurotransmissores no sistema nervoso central. Aproximadamente $95 \%$ do glutamato proveniente da dieta é metabolizado no intestino originando compostos como a glutationa, arginina e prolina (REEDS et al., 2000). Nas células da mucosa intestinal o GLU é parcialmente transformando em alanina, enquanto no fígado é convertido à glicose e lactato (BRANEN et al., 2002; MALLICK, 2007).

O GMS é utilizado como aditivo alimentar capaz de emprestar um gosto diferenciado aos alimentos reconhecido como "umami", expressão em japonês que significa "saboroso" (SOLMS, 1969; KAWAMURA e KARE, 1987). Postula-se que o "umami" seria um quinto gosto básico e desde que o GMS foi reconhecido como realçador de sabor são crescentes suas aplicações na indústria alimentícia (KAWAMURA e KARE, 1987; KAWAMURA et al., 1991). O GMS apresenta uma crescente demanda industrial e alcançou no ano de 2007 uma produção anual estimada em 2 milhões de toneladas (SANO, 2009).

A apresentação comercial do GMS é composta de cristais brancos de extensa solubilidade em água e limitada dispersão em alimentos gordurosos devido suas características iônicas (BRANEN et al., 2002). Este realçador de sabor também é reconhecido como INS-621, código que corresponde à identificação no Sistema Numérico Internacional de Aditivos Alimentares elaborado pelo Comitê do Codex 
Numérico Internacional de Aditivos Alimentares elaborado pelo Comitê do Codex Alimentarius (BRASIL, 2010). Este trabalho tem como objetivo revisar as características e segurança no uso do glutamato monossódico como aditivo alimentar.

\section{OBTENÇÃO DO GLUTAMATO MONOSSÓDICO}

Kikunae Ikeda, pesquisador da Universidade de Tókio identificou em algas e proteínas de trigo um componente capaz de ofertar gosto diferenciado aos alimentos. Estudos complementares permitiram que em 1866 o GLU fosse isolado pela primeira vez por meio da hidrólise da gliadina, um peptídio encontrado no glúten do trigo, permitindo que fosse confirmada a propriedade de atuar como reaçador de sabor. Estes métodos de obtenção foram patenteados e em 1909 resultaram na produção industrial do GMS sob a denominação comercial de Ajinomoto® (AULT, 2004).

O processo utilizado do início da produção industrial até a década de 60 consistia no isolamento do GLU utilizando como matéria prima as proteínas do trigo (AULT, 2004). O método promovia a hidrólise do glúten utilizando ácido clorídrico e aquecimento durante 20 horas. A solução obtida era filtrada para remoção de produtos indesejáveis da reação entre aminoácidos e carboidratos, concentrada por $24 \mathrm{~h}$ e armazenada por aproximadamente 30 dias para cristalização do cloridrato do ácido Lglutâmico. Por fim, o pH da solução era ajustado para 3,2, ponto isoelétrico do ácido Lglutâmico, para cristalização e conversão em GMS. A obtenção do sal sódico era alcançada pela neutralização da solução ácida com $\mathrm{NaHCO}_{3}$, branqueamento utilizando carvão ativo, filtração, aquecimento e precipitação dos cristais de GMS por meio de centrifugação e posterior desidratação (SANO, 2009).

A produção deste aditivo atualmente envolve além da tradicional hidrólise do glúten, métodos de síntese química e processos fermentativos. O uso da fermentação para obtenção do GMS teve início na década de 50 quando foi observada a produção de pequenas quantidades de aminoácidos por $E$. coli motivando a identificação de outras espécies capazes de proporcionar maior produção destas macromoléculas (AULT, 2004) (Figura 2).

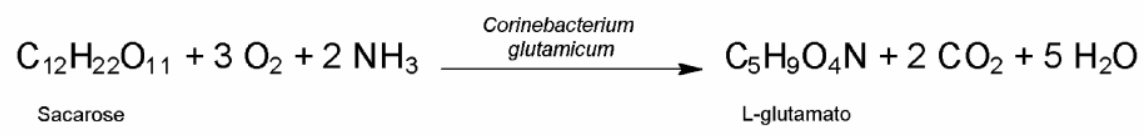

Figura 2: Produção do ácido glutâmico pelo método fermentativo a partir da sacarose

O processo de fermentação para a produção do GMS é desenvolvido por meio das bactérias Corynebacterium glutamicum, Brevibacterium lactofermentum ou Brevibacterium flavum, micro-organismos produtores da enzima glutamato 
e que utilizam como substrato meios de cultura abundantes em carboidratos e em presença de amônia (SANO, 2009). No final do processo fermentativo, o meio é esterilizado e, em seguida, centrifugado para remoção de micro-organismos e outros resíduos. A solução é então concentrada, o pH ajustado para o ponto isoelétrico do GLU $(\mathrm{pH} 3,2)$ e os cristais resultantes são convertidos em GMS, como descrito anteriormente. Após os processos de filtração, purificação, conversão e cristalização, o GMS se encontra na forma de cristais brancos aptos para uso industrial (SOBRINHO et al., 2010).

A utilização de processos fermentativos utilizando o melaço da cana-de-açúcar, como matéria prima demonstrou ser uma fonte viável para a produção de GMS em razão do custo vantajoso e elevado rendimento do processo. (SOBRINHO et al., 2010). A produção industrial do GMS por meio de processos fermentativos apresenta continua melhoraria em termos de rendimento, velocidade de produção e processo de purificação. O aprimoramento destes métodos tem otimizado a produção do GMS permitindo à indústria satisfazer à crescente demanda por este realçador de sabor (SANO, 2009).

\section{A PERCEPÇÃO DO GOSTO UMAMI}

A percepção do gosto umami, assim como do amargo e doce, é realizada por receptores de membrana, principalmente aqueles acoplados a proteína $\mathrm{G}$, responsável por intermediar a transmissão das excitações por meio de enzimas e canais iônicos. $O$ GMS em contato com células receptoras gustativas desencadeia um potencial de ação e promove a liberação de cálcio sinalizando às terminações nervosas que interpretam a resposta como um sabor específico (SAN GABRIEL et al., 2009; KINNAMON, 2009; CHAUDHARI, PEREIRA e ROPER, 2009). Postula-se ainda que o efeito realçador de sabor do GMS possa resultar de sua interação com receptores gustativos minimizando a percepção do gosto amargo (DUTCOSKY, 2007). Quando o GLU está associado à outros aminoácidos constituíndo proteínas não há promoção da percepção do gosto umami, entretanto, ao sofrer hidrólise durante o processamento, em operações que envolvam, por exemplo, o tratamento térmico, pode ser liberado e proporcionar gosto caracteristico (JINAP e HAJEB, 2010).

Estudos têm sido desenvolvidos objetivando avaliar os fatores que influenciam a sensibilidade dos humanos para percepção do GMS. Em experimento desenvolvido por KOBAYASHI e KENNEDY (2001) os provadores foram divididos em 3 grupos e receberam alimentação diferenciada por 10 dias. O primeiro grupo foi formado por 17 ocidentais submetidos a consumo de alimentos formulados com GMS. O segundo foi formado por 18 ocidentais e o terceiro constituído por 18 orientais, sendo que estas 
duas últimas equipes não foram expostas à alimentação prévia adicionada de GMS. Após o período de alimentação diferenciada, os provadores foram submetidos à avaliação de soluções contendo diferentes concentrações de GMS $(0,925 ; 1,25$ e 2,5 $\mathrm{mM})$. O grupo formado por orientais conseguiu identificar o GMS na menor concentração ofertada $(0,925 \mathrm{mM})$, seguido pelo grupo ocidental $(1,25 \mathrm{mM})$ exposto previamente a alimentação com GMS e a pior percepção foi verificada no grupo de ocidentais sem exposição prévia ao aditivo, que identificou o GMS somente nas maiores concentrações ofertadas $(2,5 \mathrm{mM})$. Segundo os autores, estes resultados demonstram que a percepção do GMS pode ser influenciada por questões genéticas, capacidade de atenção ou sensibilidade resultante do prolongado consumo do aditivo (KOBAYASHI e KENNEDY, 2001).

\section{USO DO GMS COMOADITIVO ALIMENTAR}

A culinária asiática utiliza tradicionalmente o GMS na preparação dos alimentos, porém, seu uso no ocidente há muito tempo vem sendo realizado em ampla variedade de alimentos, de carnes a vegetais, sejam em preparações caseiras ou processos industriais (HE et al., 2008).

A concentração de GMS utilizada em alimentos usualmente varia entre $0,20 \%$ a $1 \%(p / p)$ e estudos têm demonstrado que o uso em maiores concentrações não proporciona uma significativa vantagem sobre os efeitos desejados, tendendo a uma estabilização na intensidade da percepção do gosto (RODRIGUEZ, GONZÁLEZ e CENTURIÓN, 2003; JINAP e HAJEP, 2010; DURÁN-MÉRAS et al., 1993). Devido ao pronunciado efeito sinérgico do GMS com sais dissódicos, como o inosinato, encontrado principalmente em carnes e peixes, e o guanilato, encontrado em cogumelos, o GMS deve ser utilizado com moderação nestes alimentos, pois, ao interagir com estes nucleotídeos produz efeito até seis vezes superior ao esperado (DURÁN-MÉRAS et al., 1993).

As sopas industrializadas exemplificam o uso do GMS como realçador de sabor em alimentos. Avaliações realizadas por GUIMARÃES e LANFER-MARQUEZ (2005) identificaram uma ampla variação na concentração de GMS, entre 1 e $7 \%$, em diferentes apresentações de cremes e sopas, superando as concentrações próximas a $1 \%$ indicadas para uso como realçador de sabor (RODRIGUEZ, GONZÁLEZ e CENTURIÓN, 2003; DURÁN-MÉRAS et al., 1993).

Carnes e peixes são alimentos onde é característico o uso do GMS (RODRIGUEZ, GONZÁLEZ e CENTURIÓN, 2003; TERRA, 1998). O emprego nestes alimentos proporciona resultados diferenciados conforme a espécie de origem da carne. Segundo BRANEN et al. (2002) o GMS proporciona os melhores resultados 
sobre a palatabilidade quando utilizado em carnes de aves e suínos, neste produtos é empregado comumente em concentrações próximas a 0,2\% (TERRA, 1998).

O gosto umami permite que o GMS seja utilizado como substituinte do cloreto de sódio, reduzindo seu uso entre 30 e 40\% nos alimentos (YAMAGUCHI e TAKAHASHI, 1984). Este aditivo contém aproximadamente $13 \%$ de sódio em sua composição, ou seja, menos da metade do sódio presente no sal de cozinha, onde este íon constitui aproximadamente $40 \%$ da massa molecular. Porém, quando o objetivo é reduzir a concentração de sódio visando contornar problemas cardiovasculares não se pode negligenciar que o GMS, ainda que em menor concentração, também é uma importante fonte deste composto (BRANEN et al., 2002). A FAO, Organização das Nações Unidas para Agricultura e Alimentos, classifica os sais do GLU como substitutos do sal, porém, estes aditivos são compostos pelos íons cálcio, potássio, magnésio e amônio, excluindo o GMS das alternativas regulamentadas por esta instituição para substituição do cloreto de sódio (FAO, 1974).

Pacientes com câncer geralmente apresentam redução na ingestão de alimentos, dentre outros fatores, devido às alterações sensoriais decorrente da quimioterapia (BIANCHI e ANTUNES, 2008). Estudos demonstraram que o uso do GMS pode melhorar a palatabilidade auxiliando a alimentação de pacientes debilitados. Crianças portadoras de câncer e sob tratamento quimioterápico foram avaliadas quanto a capacidade de identificar diferentes concentrações de GMS, baixa (0,49-0,62 g/L), média $(0,80-1,57 \mathrm{~g} / \mathrm{L})$ e alta $(2,03-3,96 \mathrm{~g} / \mathrm{L})$. Verificou-se que a presença do GMS foi identificada pelos pacientes nas menores concentrações avaliadas, demonstrando sua capacidade de proporcionar palatabilidade mesmo sob as severas condições do tratamento (ELMAN, SOARES e PINTO E SILVA, 2010).

\section{ASPECTOS LEGAIS E SEGURANÇA NO CONSUMO DO GMS}

A maior quantidade de Glu ingerida pela população é provida na forma livre ou como componente de proteínas presentes nos alimentos e apenas uma menor quantidade é consumida na forma de GMS utilizado como aditivo (DIEMEN e TRINDADE, 2010). A segurança relacionada ao consumo deste composto tem sido avaliada por diversos estudos ao longo das últimas décadas (HE et al., 2008, ERB, 2006, GEHA et al., 2000; PRAWIROHARDJONO et al., 2000).

A "Síndrome do Restaurante Chinês" foi descrita inicialmente na década de 60 e relatava a ocorrência de sintomas como ardência no pescoço, braços e tronco, tensão em músculos faciais, dor de cabeça e lacrimejamento, possivelmente, após o consumo de alimentos formulados com GMS. Estudos têm sido desenvolvidos para identificar uma eventual relação entre o consumo de GMS e a Síndrome do Restaurante Chinês, 
neste contexto, um amplo estudo avaliando 130 pessoas que relatavam hipersensibilidade ao GMS, quando expostas a alimentação formulada com o aditivo, não demonstrou resultados capazes de estabelecer uma relação entre o consumo deste composto e a ocorrência da síndrome (GEHA et al., 2000; PRAWIROHARDJONO et al., 2000).

Outro estudo a fim de verificar uma possível relação entre o consumo de GMS e a síndrome do restaurante chinês foi desenvolvido na Indonésia, com a participação de 52 voluntários saudáveis. Por um período de 3 dias, previamente ao almoço, estes voluntários ingeriram cápsulas contendo de 1,5 a 3,0g de GMS ou ainda um placebo contendo apenas lactose. Posteriormente, os participantes deveriam relatar a ocorrência de sintomas, como dor de cabeça e náuseas. Os resultados não apresentaram diferenças significativas demonstrando que o consumo de GMS não promoveu os indesejáveis sintomas relatados na síndrome do restaurante chinês (PRAWIROHARDJONO et al., 2000).

A possível associação entre o consumo deste aditivo com o desenvolvimento ou agravamento da asma, foi descartada conforme estudo realizado em ratos induzidos à asma. A administração por via oral de GMS, não exerceu nenhum efeito sobre a situação induzida, seja no desenvolvimento ou na ocorrência de uma resposta aguda (YONEDAet al., 2011).

Alguns autores relataram que o GMS possa estar relacionado ao desenvolvimento de doenças crônicas como obesidade, diabetes, transtorno do déficit de atenção com hiperatividade, autismo, epilepsia, além de ser genotóxico a vários orgãos (HE et al., 2008, ERB, 2006). Estudos avaliando a administração de GMS via subcutânea em ratos recém-nascidos demontrou o surgimento de lesões no núcleo hipotalâmico (BUNYAN, MURREL e SHAH 1976; YOSHIDA et al., 1984). No entanto, as avaliações sobre possíveis efeitos tóxico do GMS têm demonstrado que nas concentrações como é habitualmente consumido este aditivo não representa perigo aos consumidores (BEYREUTHERI et al. , 2006).

As principais agências reguladoras que normatizam a produção de alimentos não estimam concentrações limite para o uso do GMS, porém determinam que sua utilização deva ser informada no rótulo dos produtos (FAO, 1974; FDA, 2006; BRASIL, 2001). Segundo estudos compilados pela FAO, o uso de GMS nas concentrações utilizadas em alimentos não representa perigo aos consumidores, com ressalvas a alimentos destinados a crianças menores de um ano, que em razão da carência de de estudos, sugere-se que não seja utilziado (FAO, 1974). Nos Estados Unidos, o Food and Drug Administration (FDA), em consonância com a FAO, limita o uso deste aditivo em alimentos para crianças de primeira infância (FDA, 2006).

No Brasil, a ANVISA regulamenta o GMS com a função de realçador de sabor em 
alimentos e permite seu uso em quantidades suficientes para que se obtenham os efeitos desejáveis, podendo ser empregado em molhos, carnes, caldos de carne e sopas, dentre uma grande diversidade de alimentos (BRASIL, 2001). O uso em produtos cárneos, possivelmente a classe de alimentos onde é utilizado em maior volume, é regulamentado pela Portaria n 1.004, de 11 de Dezembro de 1998 que permite seu uso na maioria dos derivados cárneos e não impõe limites para as concentrações utilizadas (BRASIL, 1998).

\section{CONCLUSÃO}

O GMS é um aditivo amplamente utilizado como realçador de sabor em alimentos. O emprego de processos fermentativos otimizou sua produção e assegurou o suprimento da crescente demanda promovida pela indústria alimentícia. Exceto em produtos destinados a crianças menores de um ano, que ainda requerem maiores estudos, o GMS mostrou-se um aditivo seguro nas concentrações comumente utilizadas em alimentos e seu uso é regulamentado pelas principais agências reguladoras.

\section{REFERÊNCIAS}

AULT, A. The monosodium glutamate story: the commercial production of MSG and other amino acids. Journal of Chemical Education, 81(3), pp. 347-355, 2004

BEYREUTHER, K., BIESALSKI, H.K., FERNSTROM, J.D., GRIMM, P., HAMMES, W.P., HEINEMANN, U. Consensus meeting: monosodium glutamate-an update. European Journal of Clinical Nutrition, 61(3), pp. 304-313, 2007.

BRANEN, A. L., DAVIDSON, P. M., SALMINEN, S., THOMGATE III, J.H. Food Additives: Second edition Revised and Expanded. New York: Marcel Dekker, 2002. pp. 409-445.

BRASIL. Agência Nacional de Vigilância Sanitária. Sistema Internacional de Numeração de Aditivos Alimentares. Brasília, 2001. Disponível em: <http://www.anvisa.gov.br/ alimentos/aditivo.htm>Acesso em: 22 dez. 2010.

BRASIL. Agência Nacional de Vigilância Sanitária. Portaria n 1004, de 11 de dezembro de 1998. Regulamento técnico que aprova o uso de aditivos e seus limites máximos em 
carnes e produtos cárneos. Diário Oficial da União. Brasília, Seção 1, pp. 28, 14 dez. 1998.

BRASIL. Agência Nacional de Vigilância Sanitária. Resolução-RDC n. 1, de 2 de janeirode 2001. Regulamento técnico que aprova o uso de aditivos com a função de realçadores de sabor, estabelecendo seus limites máximos para os alimentos. Diário Oficial da União. Brasília, Seção 1, pp. 21, 4 jan. 2001.

BUNYAN, J., MURREL, E.A., SHAH, P.P. The induction of obesity in rodents by means of monosodium glutamate. British Journal of Nutrition. 35(1), pp. 25-39, 1976.

CHAUDHARI, N., PEREIRA, E., ROPER, S.D. Taste receptors for umami: the case for multiple receptors. American Journal of Clinical Nutrition, 90, pp. 738-742, 2009.

DIEMEN, V.V., TRINDADE, M.R.M. Effect of the oral administration of monosodium glutamate during pregnancy and breast-feeding in the offspring of pregnant wistar rats. Acta Cirúrgica Brasileira. 25(1), pp. 37-42, 2010.

DURÁN-MERÁS, I., PEÑA, A.M., ESPINOSA-MANSILLA, A., SALINAS, F. Multicomponent determination off flavor enhancers in food preparations by partial least squares and principal component regression modeling of spectrophotometric data. Analyst, 118(7), pp. 807-813, 1993.

DUTCOSKY, S.D. Análise sensorial de alimentos. Curitiba: Universitária Champagnat, 2007.

ELMAN, I., SOARES, N.S., PINTO E SILVA, M.E.M. Análise da sensibilidade do gosto umami em crianças com câncer. Revista Brasileira de Cancerologia, 56(2), pp. 237242, 2010.

ERB, J. A report on the toxic effects of the food additive monosodium glutamate to the Joint FAO/WHO Expert Committee on Food Additives. Canadian, 2006.

FAO/WHO. Toxicological evaluation of food additives with a review of general principles and specifications. $17^{\text {th }}$ Report of the Joint FAO/WHO Expert Committee on Food Additives. FAO Nutrition Meetings Report Series n.53, WHO Technical Reports Series n. 539, 1974. 
FDA - Food and Drug Administration Data-base of Select Committee on GRAS Substances (SCOGS) Reviews, 2006. Disponível em: <http://www.fda.gov/Food/ FoodIngredientsPackaging/GenerallyRecognizedasSafeGRAS/GRASSubstancesSC OGSDatabase/default.htm>Acesso em: 13 dez. 2010.

GEHA, R.S., BEISER, A., REN, C., PATTERSON, R., GREENGERGER, P.A., GRAMMER, L.C. Review of alleged reaction to monosodium glutamate and outcome of a multicenter double-blind placebo-controlled study. Journal of Nutrition, 130(45), pp. 1058-1062, 2000.

GUIMARÃES, C.P., LANFER-MARQUEZ, U.M. Estimativa do teor de fenilalanina em sopas desidratadas instantâneas: importância do nitrogênio de origem não-protéica. Revista Brasileira de Ciências Farmacêuticas, 41(3), pp. 365-375, 2005.

HE, K., ZHAO, L., DAVIGLUS, M.L., DYER, A.R., HORN, L.V., GARSIDE, D. Association of monosodium glutamate intake with overweigth in Chinese adults. The Intermap Study. Obesity, 16(8), pp. 1875-1880, 2008.

JINAP, S., HAJEB, P. Glutamate: Its applications in food and contribution to health. Appetite, 55(1), pp.1-10, 2010.

KAWAMURA, Y., KARE, M.R. UMAMI: a basic taste. New York: Marcel Dekker, 1987.

KAWAMURA, Y., KURIHARA, K., NICOLAIDIS, S., OOMURA, Y., WAYNER, M.J. Umami: proceeding of the second international symposium on umami. Physiology \& Behavior, 49, pp. 833-1030, 1991.

KINNAMON, S.C. Umami taste transduction mechanisms. American Journal of Clinical Nutrition, 90, 753-755, 2009.

KOBAYASHI, C., KENNEDY, L.M. Experience-induced changes in taste identification of monosodium glutamate (MSG). Physiology \& Behavior, 75(1-2), pp. 57-63, 2001.

MALLICK, H.N. Review article. Safety of glutamate in food and brain. Indian Journal of Physiology and Pharmacology. 51(3), pp. 216-234, 2007.

PRAWIROHARJONO, W., DWIPRAHASTO, I., ASTUTI, I., HADIWANDOWO, S., KRISTIN, E., MUHAMMAD, M., KELLY, M.F. The administration to Indonesians of 
Monosodium L-Glutamate in Indonesian Food: Na Assessment of Adverse Reactions in a Randomizes Double-Blind, Crossover, Placebo-Controlled Study. Journal of Nutrition, 130, pp. 1074-1076, 2000.

REEDS, P.J., BURRIN, D.G., STOLL, B., JAHOOR, F. Intestinal glutamate metabolism. Journal of Nutrition, 130, pp. 978-982, 2000.

RODRIGUEZ, M.S., GONZÁLEZ, M.E., CENTURIÓN, M.E. Determination of monosodium glutamate in meat products. The journal of the Argentine Chemical Society, 91(4/6), pp. 41-45, 2003.

SAN GABRIEL, A., MAEKAWA, T., UNEYAMA, H., TORII, K. Metabotropic glutamate receptor type 1 in taste tissue. American Journal of Clinical Nutrition, 90, 743-746, 2009.

SANO, C. History of glutamate production. American Journal of Clinical Nutrition, 190, pp. 728-732, 2009.

SOBRINHO, R.S., SCHVARZ, L.H.C., SALÉ, N.A.C., AMARAL, M.R.S., BORTOLI, E.C. Contribuição da cadeia produtiva de cana-de-açúcar ( Saccharum officinarum) no sabor dos alimentos. Ambiência-Revista do Setor de Ciências Agrárias e Ambientais. 6(1), pp. 37-46, 2010.

SOLMS, J. The taste of amino acids, peptides, and proteins. Journal of Agricultural and Food Chemistry, 17, pp. 686-688, 1969.

TERRA, N.N. Apontamentos de tecnologia de carnes. São Leopoldo: Unisinos, 1998.

YAMAGUCHI, S. The umami taste. In: Food Taste Chemistry (Boudreau, J.C.ed.). American Chemical Society, Washington D.C., pp. 33-51, 1979.

YAMAGUCHI, S., TAKAHASHI, C. Interactions of monosodium glutamate and sodium chloride on saltiness and palatability of clear soup. Intermap Study. Obesity, 49(1), pp.

82-85, 1984.

YONEDA, J., CHIN, K., TORII, K., SAKAI, R. Effects of oral monosodium glutamate in mouse models of asthma. Food and Chemical Toxicology, 49(1), pp. 299-304, 2011. 
YOSHIDA, T., NISHIOKA, H., KONDO, M. Reduced norepinephrine turnover in mice with monosodium glutamate-induced obesity. Metabolism, 33, pp. 1060-1063, 1984. 